\title{
THE MOVEMENT OF AORTIC AND PULMONARY VALVES STUDIED POST MORTEM BY COLOUR CINEMATOGRAPHY
}

BY

\author{
I. K. R. McMILLAN*, R. DALEY, AND M. B. MATTHEWS \\ From the Cardiac Department, St. Thomas's Hospital
}

Received August 22, 1951

This paper describes a method of studying the action of human pulmonary and aortic valves obtained shortly after death. The aim was to study the action of human heart valves in an artificial system, the flow through which was designed to resemble that in the living heart. In this way it was hoped to obtain information that might apply to human surgical problems.

The need for knowledge of valve action is becoming greater as surgical treatment of pathological aortic and pulmonary valves becomes established. The majority of surgical techniques in this field have been evolved from morbid anatomical studies and experiments on living animals. Recent work by Bailey et al. (1950) and Brock (1950) illustrates the difficulties of surgical approach to aortic stenosis.

Particular attention has been paid to the behaviour of normal and abnormal valves with alterations of flow and rate. A preliminary study of the action of stenosed aortic valves before and after division of fused commissures has been made. A similar study has been reported by Smith et al. (1950), but their experiments were mainly concerned with photographing valve action in the experimental animal.

Method. Fresh hearts were obtained from the post-mortem room with the ascending aorta cut across about one inch above the aortic valve. Fig. 1 shows the method of setting up the preparation. The ascending aorta was fixed round the perspex tube below the viewing chamber by a ligature at A. A threaded metal tube, B, was tied into the left ventricle in the apical region and passed through a plate, $C$, into the chamber, $D$. By screwing the nut, $N$, the heart was stretched taut between aorta and apex. The nut also made a water-tight joint between $\mathrm{D}$ and the space $\mathrm{E}$ round the heart which was open to the atmosphere. In this way fluid from $D$ could pass through the pipe into the ventricular cavity, through the aortic valves into the viewing chamber, $F$, and out to the " peripheral circulation."

Movement of the valves was photographed by a cine-camera placed over the viewing chamber. The peripheral circulation consisted of a vertical tube filled with water, the top of which was open to the atmosphere. A closed air-filled side arm was incorporated in order to simulate the elastic recoil of the aorta. Variations in the height of the column altered the pressure against which the system had to work. The apparatus was perfused with water under constant pressure from an outside source. An electrically operated solenoid valve, G, controlled the flow into chamber, D. A similar valve, $\mathrm{H}$, controlled the outflow to the atmosphere.

$G$ and $H$ were controlled by an electronic switch, $I$. When $G$ was open, $H$ was shut, and vice versa, and so an intermittent flow was obtained. The proportion of inflow to outflow time could be altered, and also the overall rate.

The camera used was an electrically operated cine-camera specially adapted for photographing objects through water at a range of six inches.

* Assisted by a grant from the Endowment Fund of St. Thomas's Hospital. 


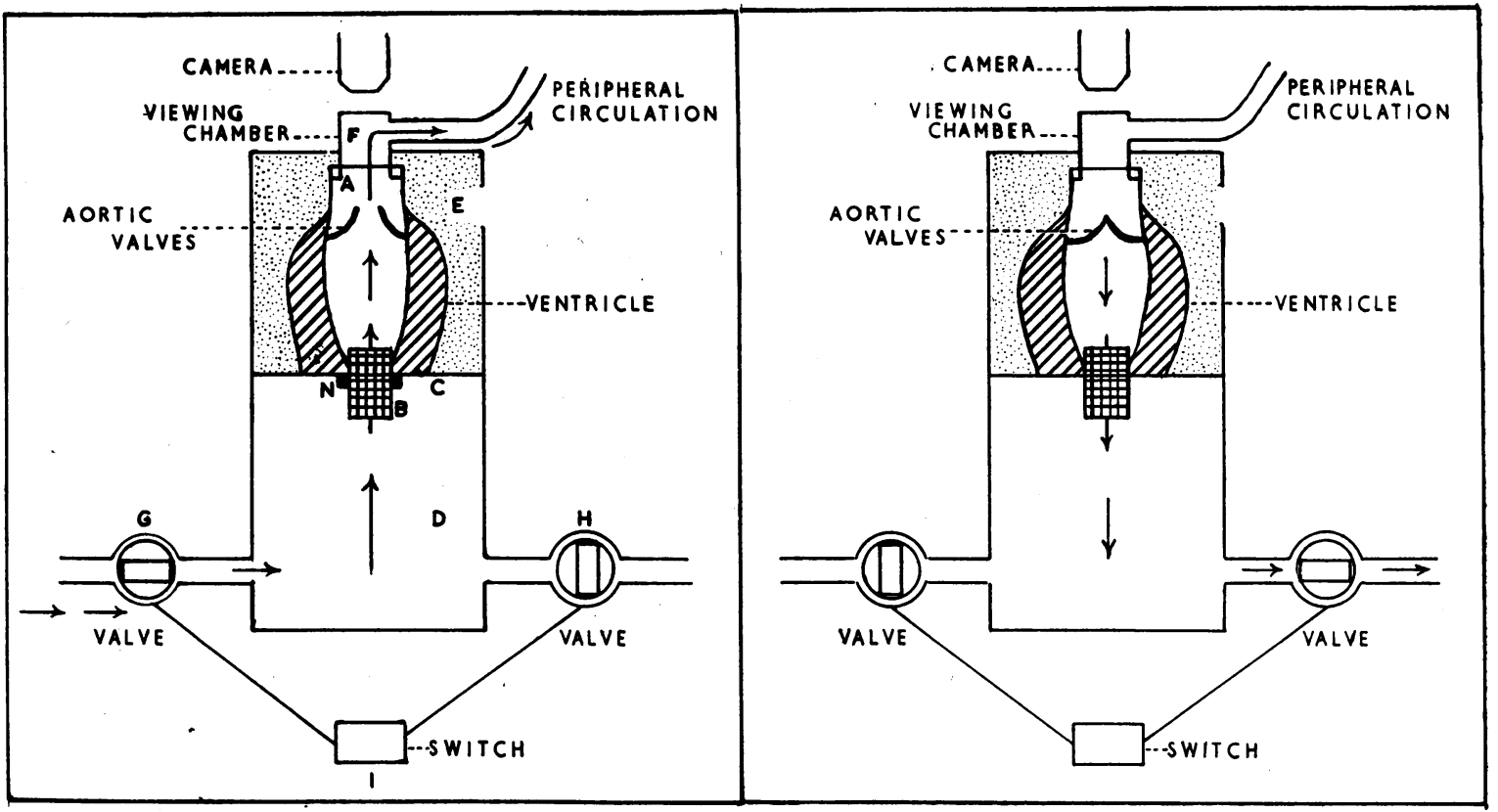

SYSTOLE.

A

DIASTOLE.

B

FIG. 1.-Diagram of system with valves arranged to correspond to systole (A) and to diastole (B).

\section{RESULTS}

A maximum intermittent flow of three litres through the valves was obtained. The aortic valves closed as soon as the intraventricular pressure fell sufficiently. When normal aortic valves were used pressures distal to the valve of about $120 \mathrm{~mm} . \mathrm{Hg}$ "systolic" and $80 \mathrm{~mm} . \mathrm{Hg}$ " diastolic " could be obtained. There was also a prominent dicrotic notch when the valves closed. Pressures in the chamber proximal to the valves were about $120 \mathrm{~mm}$. systolic falling to $0 \mathrm{~mm}$. diastolic. Pressures were recorded with a Sanborn electromanometer. Pressures were not recorded before and after division of commissures in stenosed bicuspid and stenosed aortic valves, but following commissure division the flow through the valves increased in two experiments from 2 to 3 litres a minute in the stenosed aortic valve and from $1 \frac{1}{2}$ to $2 \frac{1}{2}$ litres a minute in the stenosed bicuspid aortic valve. Cinematograph films have been made of the following conditions (Fig. 2 and 3).

(1) Normal aortic valves. (2) An aortic valve believed to be incompetent in life. (3) A stenosed aortic valve before and after division of the fused commissures. (4) A bicuspid aortic valve before and after division of the fused commissure. (5) A normal pulmonary valve.

\section{Discussion}

Aortic and pulmonary valves have a simple mechanical action. In order to approximate as nearly as possible to the conditions under which they behave in man the following factors should be considered.

Flow. Three litres a minute is the maximum so far obtained but it is hoped to increase this considerably and it should be possible eventually to obtain flows approximating to the human cardiac output during moderate exercise.

Pressure distal to the valves. This was controlled by the height of the peripheral column and was readily adjustable. The pressures were arranged to be as near as possible to those in life. It is 


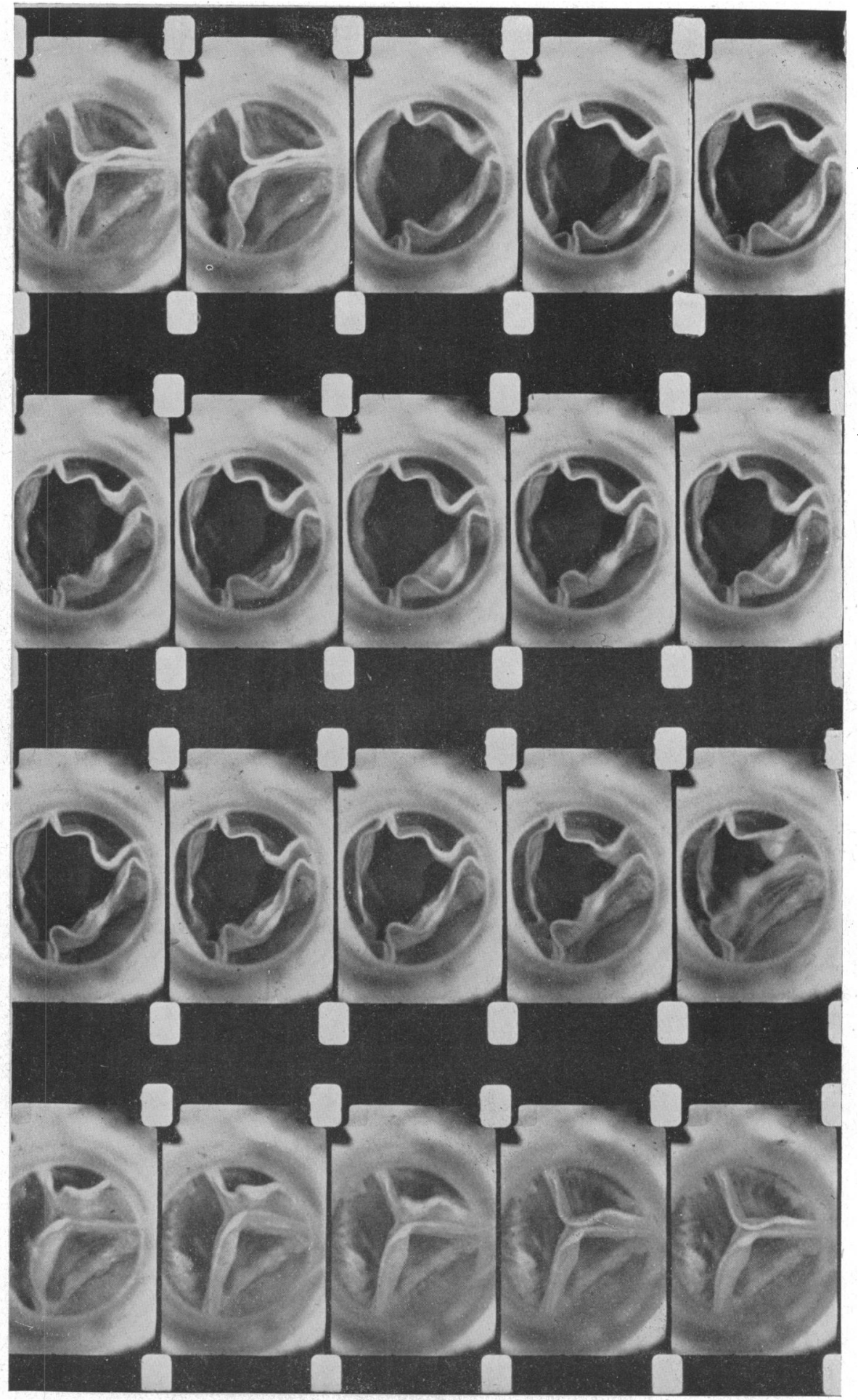

FIG. 2.-Normal aortic valve. Photographs from the film showing a complete cycle of opening and closing. 
FIG. 3.-(1) Pulmonary valve shut and (2) open. (3) Aortic valve from a patient who had evidence of aortic incompetence in life. (4) Bicuspid aortic valve open, and (5) shut and (6) with commissure divided. (7) Aortic valve with calcified plaques in the cusps. (8) Stenosed aortic valve and (9) the same valve with commissures divided. 
technically difficult to reproduce in a model a peripheral resistance that is at all similar to the peripheral resistance of man. We are aware of the present limitations of the apparatus. -

Rate. As already described this was controlled by the electronic switch.

Viscosity. This problem has not yet been studied but experiments are proceeding using translucent fluids of viscosity approximating to the viscosity of blood.

It has been possible so far to perfuse a normal heart under the following conditions-a flow of three litres a minute maximum, pressures comparable to normal blood pressures, and rates between 60 and 80 a minute. From this it is apparent that the pressure can be satisfactorily arranged. It is hoped to increase flow and rate and to study the problem of viscosity. By this method; variations in these four factors can be arranged to comply with the known clinical data of the specimen under trial.

Division of two stenosed valves has produced an increase in flow. With this encouragement it is proposed to extend the study of the effects of operations on stenosed valves and the efficiency of plastic operations for repair of incompetent valves. These manœuvres can be carried out with human material, such as pericardial or fascial grafts, or with prostheses. Successful procedures can be further studied on experimental animals as a step in the evolution of human operative treatment.

\section{SUMMARY}

A method is described of intermittent perfusion of human hearts post-mortem and of photographing the action of the aortic and pulmonary valves.

Films were made of normal aortic and pulmonary valves and of stenosed, bicuspid, and incompetent aortic valves.

The physiological factors that need to be reproduced are discussed. Suggestions are made for future work.

Our thanks are due to Professor W. G. Barnard, Dr. L. Hewlett and Dr. D. Teare for access to the pathological material. We would like to express our grateful thanks to Dr. Evan Jones for his interest. We would also like to thank Mr. P. Stiles for the design of the switch and to Messrs. B. J. Lynes, A. E. Clarke, F. Thomas, R. W. Halls and A. L. Wooding for technical assistance.

\section{REFERENCES}

Bailey, C. P., Glover, R. P., O'Neill, T. J. E., and Ramirez, H. P. R. (1950), J. thoracic Surg., $20,516$.

Brock, R. C. (1950). Guy's Hosp. Rep., 99, 236.

Smith, H. L., Essex, E., and Baldes, E. J. (1950). Ann. intern. Med., 33, 1357. 